Original Research Paper

\title{
Potential of HMEC-1 Line and HUVEC Primary Culture Cells to Study the Neonatal IgG Fe Receptor in vitro
}

\author{
${ }^{1,2}$ Luz Belinda Ortiz-Alegría, ${ }^{1}$ Irma Cañedo-Solares, \\ ${ }^{3}$ Felipe Vadillo-Ortega, ${ }^{3}$ Marisol Castillo-Castrejón and ${ }^{1}$ Dolores Correa \\ ${ }^{1}$ Laboratorio de Inmunología Experimental, Subdirección de Medicina Experimental, \\ Instituto Nacional de Pediatría, Secretaría de Salud, México D.F., México \\ ${ }^{2}$ Doctorado en Ciencias Biomédicas, Universidad Nacional Autónoma de México, México D.F., México \\ ${ }^{3}$ Unidad de Vinculacion de la Facultad de Medicina de la Universidad Nacional Autónoma de México en el Instituto Nacional \\ de Medicina Genómica, México D.F., México
}

Article history

Received: 15-01-2016

Revised: 19-03-2016

Accepted: 21-03-2015

Corresponding Author:

Dolores Correa

Laboratorio de Inmunología

Experimental, Subdirección de

Medicina Experimental,

Instituto Nacional de Pediatría,

Secretaría de Salud, México

D.F., México

Tel: +52 (55) 10840900,

Ext: 1860 or 1873

Email: mariadol@yahoo.com

\begin{abstract}
The neonatal IgG Fc receptor (FcRn) plays an important role in IgG homeostasis and immunity passive transfer. Fine points regarding these mechanisms, however, are still emerging. In order to obtain information about these phenomena, it is essential to have in vitro models of endothelium that express this receptor. In this study we chose two widely used models of human endothelial cells: the semi-immortalized and stable cell line HMEC-1 (CDC/USA) and the Human Umbilical Vein Endothelial Cells (HUVECs) which maintain morphological, phenotypical and functional characteristics of human micro and macro-vasculature endothelia, respectively. We found that both cells express the FcRn mRNA and protein using real-time RT-PCR, flow cytometry and confocal microscopy, respectively. We detected differences in mRNA expression levels in HUVECs among individuals. The protein was found on the cell surface but also intracellularly within vesicles. This study supports the use of two cell types as models of FcRn expression, allowing either to understand or to manipulate the mechanisms in which the receptor is involved in vivo.
\end{abstract}

Keywords: FcRn, Endothelial Cells, HMEC-1, HUVECs

\section{Introduction}

Half a century ago Francis Brambell and collaborators proposed that a saturable receptor for Fc of $\mathrm{IgG}(\mathrm{FcRn})$ was responsible both for transcytosis across the intestinal epithelium or the placenta and for protection of IgG from catabolism, extending its half-life in serum (Brambell et al., 1964).

This receptor, composed by an alpha chain (FCGRT) in association with Beta-2-Microglobulin (B2M), is expressed in different cell types of various organs and systems, in a wide variety of animal species, but endothelial cells are considered the main mediators of FcRn-IgG processes (Johnson et al., 1975; Rodewald, 1980; Ghetie et al., 1996; Borvak et al., 1998; Cianga et al., 2011; Rath et al., 2013). It has been demonstrated in endothelial cells of the lung, term placenta villi and retino-choroids (Borvak et al., 1998; Antohe et al., 2001; Ward et al., 2003; Radulescu et al., 2004; Perez-Montoyo et al., 2009;
Powner et al., 2014). The FcRn thus seems widely distributed in the human body. It is constitutively expressed, is up-regulated by TNF- $\alpha$ and LPS and down-regulated by IFN- $\gamma$ (Liu et al., 2007; 2008).

Although, there are many recent articles related to FcRn, most are focused in therapeutic uses. Several advances in engineering antibodies had been made, for half-life delay and $\mathrm{pH}$-dependent binding, with consequent improvements in efficacy (Ward et al., 2015). Also, the inhibition of FcRn reduces $\operatorname{IgG}$ levels in the organism and clears pathogenic and autoreactive antibodies, ameliorating some diseases, like idiopathic thrombocytopenic purpura, myasthenia gravis, arthritis and multiple sclerosis in mouse models (Ellinger and Fuchs, 2012; Ward et al., 2015). Nevertheless, these studies have not been confirmed in humans and little is known in relation to expression levels in many cell subtypes, or whether it performs the same functions. The FcRn is an unusual receptor, because it binds $\operatorname{IgG}$ at acidic $\mathrm{pH}$; however, specific mechanisms remain to be 
elucidated (Rath et al., 2013). It is not clear whether IgG uptake occurs via fluid phase pinocytosis or whether this is a receptor-mediated phenomenon at the surface level; neither is it certain whether this mechanism depends on the cellular type. Knowledge about how FcRn carries out its function in human cells is of relevance to understand how IgG levels are regulated (Borvak et al., 1998).

FcRn not only binds to monomeric IgG but also to antigen/antibody complexes. In some cases it facilitates efficient immune responses towards opsonized antigens or pathogens (Johnson et al., 1975; Qiao et al., 2008; Baker et al., 2012; 2014). In other cases this route could serve microorganisms to traverse epithelial barriers, e.g., Cytomegalovirus covered with human $\mathrm{IgG}$, is suggested to traverse the syncytiotrophoblast and the fetal endothelium at the villi, reaching the fetus (Maidji et al., 2006). Likewise, HIV-1 transcytosis across epithelia is enhanced by this receptor (Gupta et al., 2013). Furthermore, IgG transfer offers opportunities for delivery of therapeutic antibodies or coupled proteins, so it is of great interest to examine and characterize the FcFcRn interaction on IgG transport, due to its potential effect on their in vivo pharmacokinetic dynamics (Mathur et al., 2013).

In order to examine these phenomena at sub-cellular level and their regulation, in vitro cultures of endothelial cells expressing FcRn would be useful. Two widely used models of human endothelial cells are the semiimmortalized and stable cell line HMEC-1 (CDC/USA) obtained and transformed in 1992 by Ades et al. (1992) and the Human Umbilical Vein Endothelial Cells (HUVECs), originally isolated by Jaffe et al. (1973). The first shares similar morphological, phenotypical and functional characteristics with human microvascular endothelial cells (Ades et al., 1992; Xu et al., 1994; Unger et al., 2002). Even though they have been used to assess the intracellular route of the FcRn protein by means of transfection experiments with the gene recombined to green fluorescent protein, it has not been reported that these cells are able to express the endogenous gene (Ober et al., 2004a).

The second cell type is probably the most frequently used model of normal human endothelia, since it is more readily available than those obtained from other vessels, is commonly free of pathological processes and is physiologically relevant (Marin et al., 2001; Lang et al., 2003). The presence of FcRn has been shown in endothelial cells of the arteries and the vein of cord samples by immunohistochemistry (Zhao et al., 2011). Yet, the location and function of the FcRn in these cells are unknown; this is relevant because they form the wall of large vessels, where these aspects are intriguing.

Thus, we performed assays to determine the expression (both messenger and protein) and location of this receptor in HMEC-1 and HUVECs and present our findings in the following pages.

\section{Materials and Methods}

\section{Human Cords and Ethical Aspects}

This project was sanctioned by the Research and Ethics Committees of the National Institute of Pediatrics, of the Ministry of Health of Mexico (No.060/2011), which abides by national and international research regulations.

HUVECs were isolated from seven term human cords (38-40 gestation weeks) from indicated caesarean delivery, with neither active labor nor clinical or microbiological evidence of infection. Patients were recruited at the Hospital Materno Infantil Inguaran of the Ministry of Health of Mexico City, Mexico and gave their informed consent. Samples were immediately transferred to suitable media composed by M199 medium (Invitrogen, Life Technologies, Grand Island, USA), an antibioticantimycotic mixture $\left[100 \mathrm{U} \mathrm{mL}^{-1}\right.$ penicillin, $100 \mu \mathrm{g} \mathrm{mL}^{-1}$ streptomycin sulfate and $0.25 \mu \mathrm{g} \mathrm{mL} \mathrm{m}^{-1}$ amphotericin B] (Gibco/BRL, Life Technologies, Grand Island, USA) and $10 \%$ heat-inactivated fetal calf serum (FCS, Hyclone Logan, Utah, USA); and transported in sterile conditions to the laboratory within one hour after collection.

\section{Cell Culture}

Isolation of HUVECs was carried out according to the procedure described by Paez et al. (2005). Briefly, cells were collected by $0.2 \%$ collagenase type II digestion (Roche, Hertfordshire, UK) for $30 \mathrm{~min}$ at $37^{\circ} \mathrm{C}$, then, cells were plated on $25 \mathrm{~cm}^{2}$ cell culture flasks (Beckton Dickinson, NJ, USA) and cultured until confluence, at $37^{\circ} \mathrm{C}$ in a $7 \% \mathrm{CO}_{2}$ atmosphere, in $\mathrm{M} 199$ medium (Invitrogen, Life Technologies, Grand Island, USA) supplemented with antibiotic-antimycotic mixture (Gibco/BRL, Life Technologies, Grand Island, USA); $10 \%$ heat-inactivated FCS (Hyclone Logan, Utah, USA); $40 \mu \mathrm{g} \mathrm{mL} \mathrm{m}^{-1}$ bovine endothelial cell growth factor (bECGF; Roche, IN, USA); $5 \mathrm{IU} \mathrm{Ml}^{-1}$ porcine heparin, $10 \mathrm{mM}$ HEPES and $2 \mathrm{mM}$ L-glutamine (Sigma, St. Louis, MO, USA). Confluent HUVECs were subcultured twice after $0.05 \%$ Trypsin-EDTA treatment (Gibco, Life Technologies, Gran Island, USA); therefore, the cells used in all experiments were of the third pass (if $>95 \%$ viable). HMEC-1 cells were cultured according to Ades et al. (1992) in MCDB131 medium (Invitrogen, Life Technologies, Grand Island, USA), supplemented with $1.0 \mu \mathrm{g} \mathrm{mL}^{-1}$ hydrocortisone, penicillin $\mathrm{G}\left(100 \mathrm{IU} \mathrm{mL}^{-1}\right)$, streptomycin $\left(100 \mu \mathrm{g} \mathrm{mL}^{-1}\right)$ and amphotericin B $\left(0.025 \mu \mathrm{g} \mathrm{mL}^{-1}\right)(\mathrm{Gibco} / \mathrm{BRL}$, Life Technologies, Grand Island, USA), 10\% FCS (Hyclone Logan, Utah, USA), $10 \mathrm{mM}$ L-glutamine and $20 \mu \mathrm{g}$ $\mathrm{mL}^{-1}$ bovine endothelial cell growth factor (bECGF; Roche, IN, USA) at $37^{\circ} \mathrm{C}$, with $7 \% \quad \mathrm{CO}_{2}$, until confluence. They were detached using $0.25 \%$ Trypsin- 
EDTA (Gibco, Life Technologies, Grand Island, USA) for $2-3 \mathrm{~min}$ at $37^{\circ} \mathrm{C}$. Only cells with a maximum of four passages were used in this study. Four samples of HMEC-1 were taken from different cultures and tested to detect FcRn mRNA in triplicate. The action of Trypsin was stopped in both cases by adding media complemented with 5\% FCS and then by centrifugation (1200 rpm for seven min).

\section{FcRn $\alpha$-Chain (FCGRT) mRNA Detection by Real- Time RT-PCR}

RNA was isolated using TRIzol® (Ambion, Life Technologies, Grand Island, USA) according to manufacturer instructions, under RNase-free conditions, added directly to the culture flasks at $0.5 \mathrm{~mL} / 1 \times 10^{6}$ HMEC-1 or HUVEC cells and $1.0 \mathrm{~mL} / 100 \mathrm{mg}$ human microvilli, used as positive controls (Simister et al., 1996). The concentration and quality of extracted RNA were verified using the NanoDrop ND-1000 spectrophotometer (NanoDrop Technologies, DE, USA) and $1 \%$ agarose gel electrophoresis. cDNA was obtained by Reverse Transcription (RT) from $0.4 \mu \mathrm{g}$ total RNA, in a volume of $20 \mu \mathrm{L}$, using the TaqMan Reverse Transcription Reagents (Applied Biosystems, Life Technologies, Grand Island, USA) and according to manufacturer instructions. Validated Real time PCR primers and TaqMan probes designed by Applied Biosystems were: FCGRT (assay ID: Hs01108967 m1, FAM-MGB) and B2M (TaqMan endogenous control, RefSeq: NM_004048.2, VIC-MGB). PCR was performed in a final volume of $10 \mu \mathrm{L}$, using $5 \mu \mathrm{L}$ of $2 \mathrm{x}$ TaqMan Gene Expression Master Mix (Applied Biosystems, Foster City, CA, USA), 2.5 and $1.25 \mu \mathrm{L}$ of FCGRT and B2M TaqMan set probes, respectively and $250 \mathrm{ng}$ of cDNA per sample, in an Applied Biosystems StepOne Real-Time PCR System (Applied Biosystems, Foster City, CA, USA). Reaction conditions were: $50^{\circ} \mathrm{C}$ for $2 \mathrm{~min}, 95^{\circ} \mathrm{C}$ for $10 \mathrm{~min}$, followed by 40 cycles of $95^{\circ} \mathrm{C}$ for $30 \mathrm{~s}$ and $60^{\circ} \mathrm{C}$ for $1 \mathrm{~min}$. In some cases it was possible to obtain paired samples of placental villi and umbilical cord, which were analyzed simultaneously. The fluorescence intensity values of FCGRT and B2M were plotted; the medians were compared and the differences were calculated by Mann-Whitney U-test, considering $\mathrm{p}<0.05$ statistically significant. Relative expression changes of the FCGRT gene were calculated using the FCGRT/B2M index.

\section{FcRn a-Chain Protein Detection by Flow Cytometry and Confocal Microscopy}

Human endothelial cells were evidenced with APClabeled anti-human CD105 (endoglin) antibody, produced in mouse (BioLegend, San Diego, CA, USA) at $1: 50$ dilution $\left(25 \mu \mathrm{g} \mathrm{mL} \mathrm{m}^{-1}\right)$.

Detection of FcRn $\alpha$-chain was carried out with the antihuman FCGRT antibody, produced in rabbit (Sigma St.
Louis, MO, USA) at a 1:100 dilution and as a secondary antibody a FITC goat anti-rabbit IgG (Invitrogen, Carlsbad, USA) at $2.4 \mu \mathrm{g} \mathrm{mL}^{-1}$. As a negative control a non-related rabbit serum, at equivalent dilution, was used.

For surface immunodetection, cells were incubated with $100 \mu \mathrm{L}$ of combined primary antibodies, at $4^{\circ} \mathrm{C}$, for $30 \mathrm{~min}$ and washed with PBS. Afterwards, $100 \mu \mathrm{L}$ of FcRn secondary antibody was aggregated and cells were newly incubated at $4^{\circ} \mathrm{C}$, for $30 \mathrm{~min}$ and washed. To assess the intracellular location, both endothelial cell types were permeabilized, using the FOXP3 fix/perm buffer set solution (BioLegend, CA, USA), according to manufacturer instructions. Briefly, CD105 surface staining was done first. Afterwards, cells were incubated for $20 \mathrm{~min}$ with FOXP3 Fix/Perm solution and washed once with PBS and once again with FOXP3 Perm buffer. The pellets were resuspended in the latter, incubated for $15 \mathrm{~min}$ and centrifuged. Next, they were incubated for $30 \mathrm{~min}$ with the anti-FcRn antibody diluted in FOXP3 Perm buffer, washed twice and resuspended in PBS. All incubations were performed in the dark and at room temperature.

For flow cytometry, cells were detached from the culture dish by incubation for $3-5 \mathrm{~min}$ at $37^{\circ} \mathrm{C}$ with Trypsin-EDTA (Gibco, Life Technologies, Grand Island, USA) at 0.05 and $0.25 \%$, for HUVECs and HMEC-1, respectively. Later, $10^{5}$ cells per tube were subjected to intracellular or surface immunodetection. Finally, cells were resuspended in $0.5 \%$ buffered paraformaldehyde and analyzed on a Becton Dickinson FACSAria flow cytometer and using the FlowJo 8.3 software (San Jose CA, USA).

For confocal microscopy, cells were grown directly in 24 wells plates (Corning, NY, USA) with round coverslips (Nunc, Thermanox, NY, USA) and after confluence they were subjected to surface or intracellular immunodetection. DAPI was utilized to counterstain cell nuclei (DNA). Confocal images were captured using an Olympus FluoView ${ }^{\mathrm{TM}}$ FV1000 Confocal Laser Scanning Microscope (Olympus America Inc., NY, USA), equipped with lasers providing excitations at 405, 473, 559 and 635 $\mathrm{nm}$. The images were captured using a 60 NA oil immersion objective and processed using FV10-ASW 1.7 Viewer. All system settings were kept identical for all experiments and signal saturation was avoided. Images to be compared were always contrast-enhanced identically.

\section{Results}

\section{FcRn $\alpha$-Chain mRNA Levels}

The human FCGRT mRNA relative levels and the FCGRT/B2M index were homogeneous among HMEC1 cells of different cultures and significantly higher when compared to HUVECs and villi (Fig. 1A and 1B). These differences were not due to amounts or quality of mRNA, since the B2M endogenous control was homogeneous (Fig. 1C). 

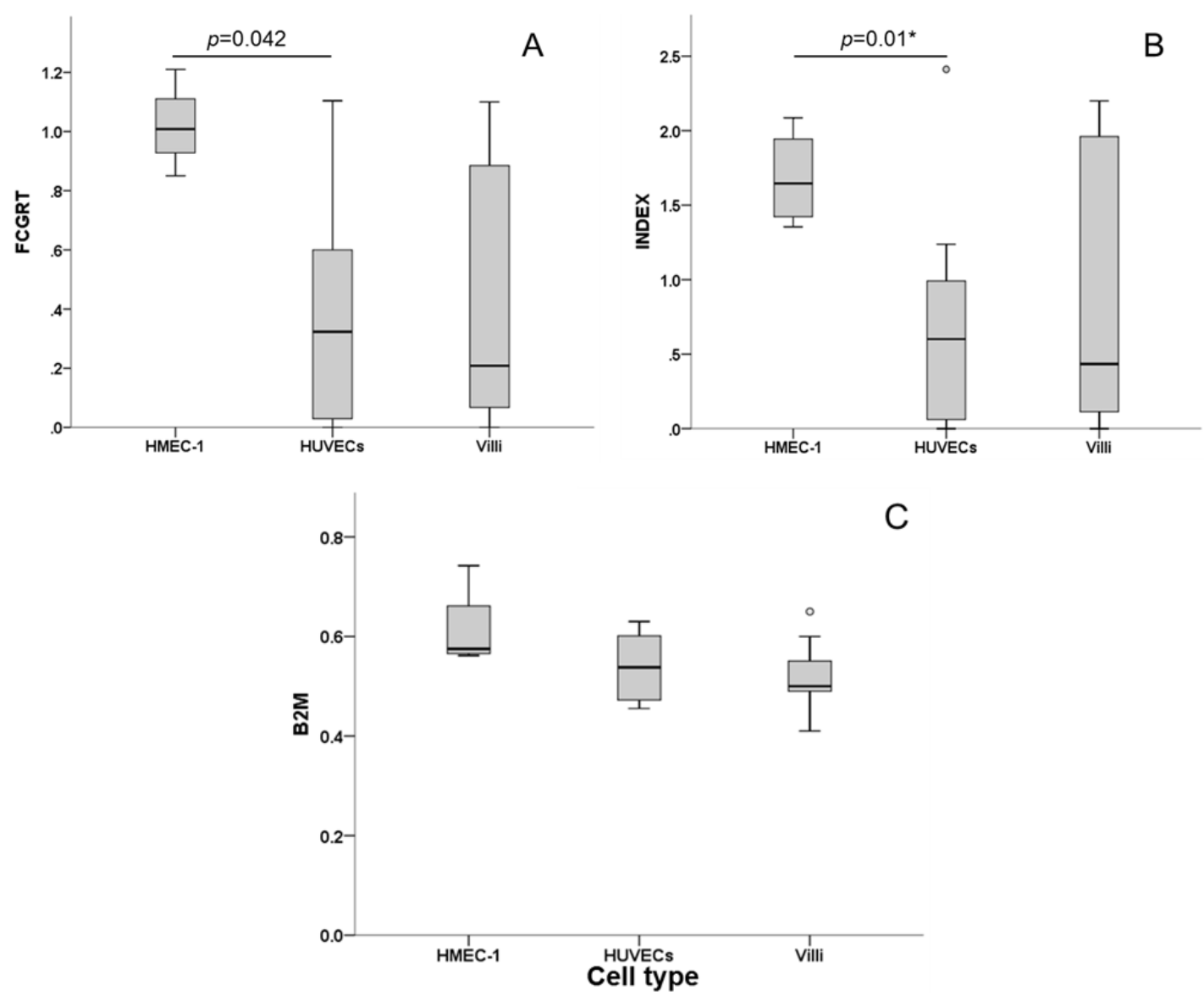

C

Fig. 1. FCGRT and B2M mRNA expression measured by semi-quantitative RT-PCR. Absolute levels (A and C) and FCGRT/B2M index $(B)$ were determined for HMEC-1 cultures $(n=4)$ or HUVECs and villi samples $(n=7$ each). Statistical significance was calculated by Mann-Whitney U-test. *This difference was calculated excluding the upper extreme value; the value including it was $p=0.074$

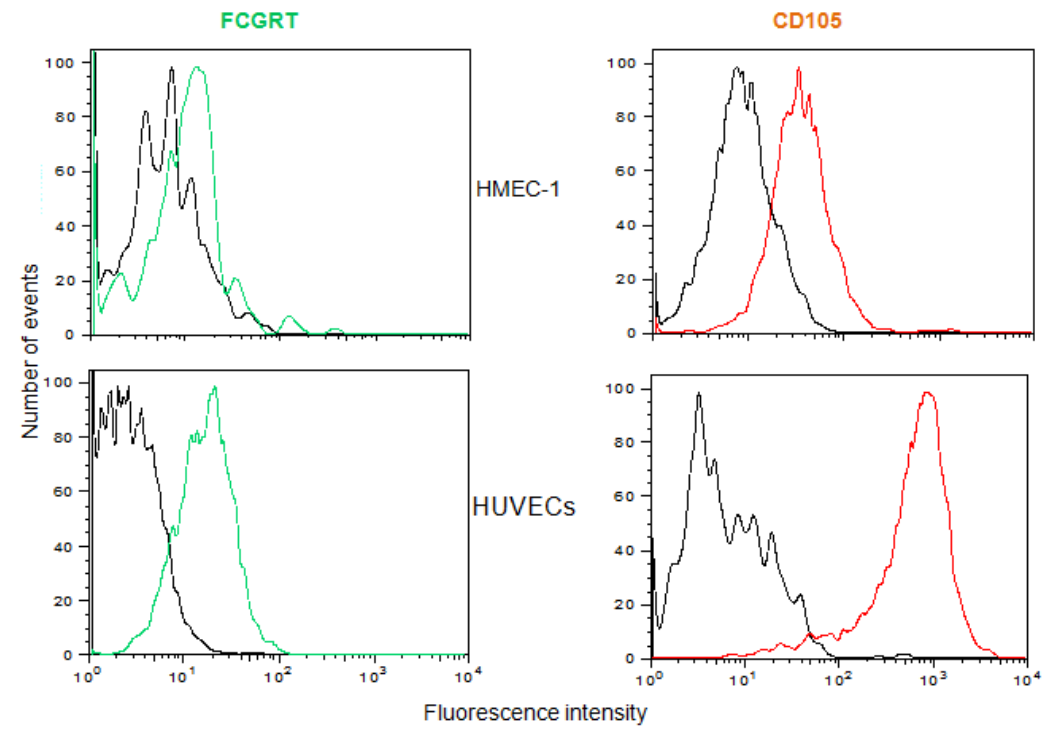

Fig. 2. Expression of the FcRn by HMEC-1 and HUVECs assessed by immunostaining and flow cytometry. Antibodies against CD105 (specific endothelial surface marker in orange) and the alpha chain of the FcRn (green) were simultaneously used to determine expression at the protein level. The black curves correspond to negative controls 


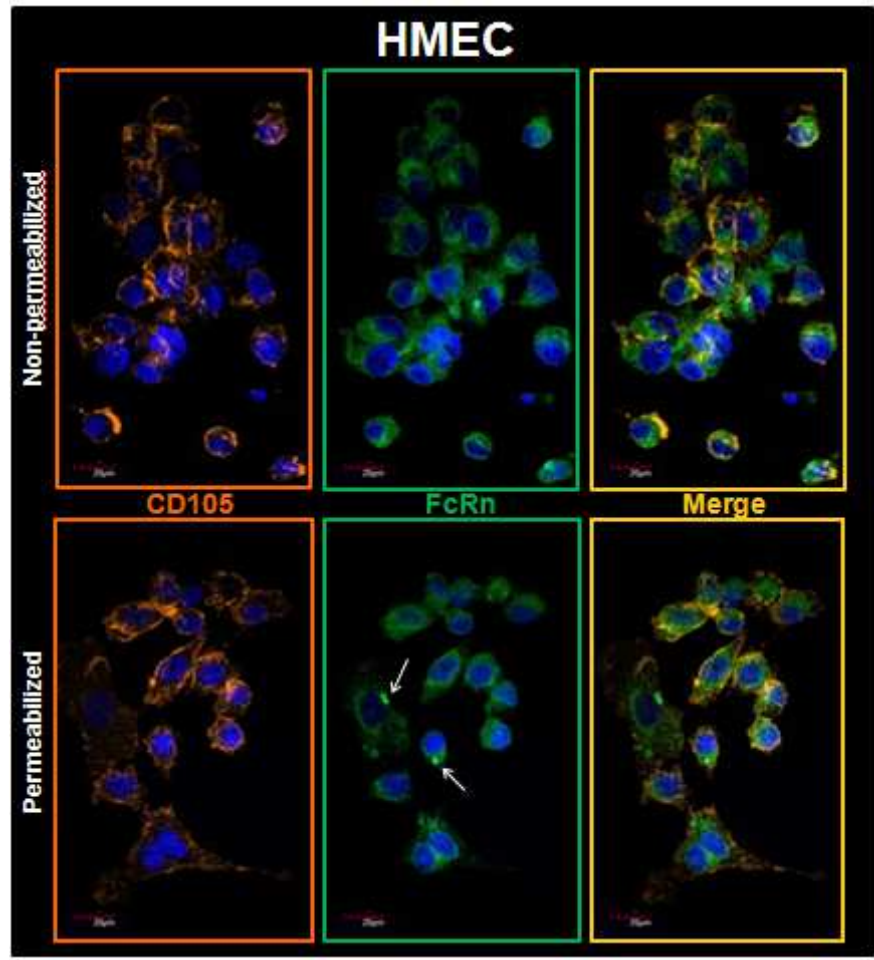

Fig. 3. Expression of the FcRn by HMEC-1 assessed by immunostaining and confocal microscopy. Antibodies against CD105 (specific endothelial surface marker in orange) and the alpha chain of the FcRn (green) were simultaneously used to determine co-localization (yellow). Nuclei are marked with DAPI (blue). Arrows point FcRn located in intracellular vesicles

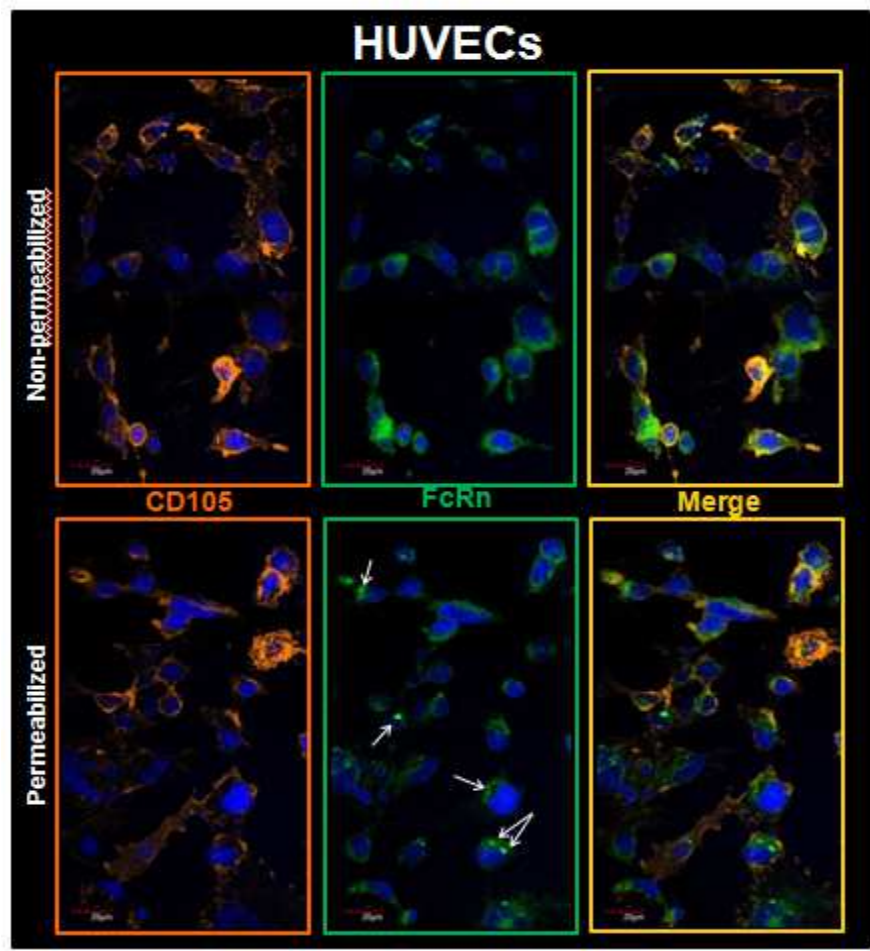

Fig. 4. Expression of the FcRn by HUVECs assessed by immunostaining and confocal microscopy. Antibodies against CD105 (specific endothelial surface marker in orange) and the alpha chain of the FcRn (green) were simultaneously used to determine co-localization (yellow). Nuclei are marked with DAPI (blue). Arrows point FcRn located in intracellular vesicles 
An aspect worth remarking is the heterogeneity of FCGRT expression among individuals who donated HUVECs or villi both determined in absolute levels or index.

\section{FcRn $\alpha$-Chain Protein Detection}

Representative cytometry graphs of human FcRn $\alpha-$ chain protein expression by HMEC-1 and HUVECs are shown in Fig. 2. As it can be observed, both cell types are positive for this protein, although HMEC-1 apparently expressed lower levels in comparison to HUVECs. However, they loom similarly stained in the confocal microscopy images; the location is also similar, co-localizing with the orange stain of CD-105 in the majority of cells (Fig. 3 and 4). The FcRn $\alpha$-chain fluorescence was throughout the cell surface; however, when the cells were permeabilized the fluorescence was also detected in the cytoplasm, including vesicles. The FcRn fluorescence intensity detected by cytometry and confocal microscopy was similar among HUVECs of different individuals (data not shown).

\section{Discussion}

Human FcRn is a receptor involved in two important mechanisms of IgG-mediated passive protection and homeostasis, described long ago: Transcytosis and internalization (Ward and Ober, 2009), which are performed by epithelial and endothelial cells (Borvak et al., 1998). It is probably also related to amelioration of pathogenic events, but this has not been confirmed in humans. Furthermore, due to controversy about sub-cellular mechanisms underlying these phenomena, it is important to have human cell models that express FcRn.

In this study we demonstrate that two varieties of human endothelial cells, HMEC-1 and HUVECs, of microvasculature and of macrovasculature, respectively, express the receptor and its location. We chose these two cell subtypes because they are easy to obtain and grow in vitro and they have specific characteristics of endothelia (Ades et al., 1992; Xu et al., 1994; Unger et al., 2002; Lang et al., 2003). Using RT-PCR, cytometry and confocal microscopy we found that both cell types express FCGRT mRNA and protein and can therefore be used as models to study processes mediated by this receptor. Zhao et al. (2011) detected the FcRn in the cytoplasm of both arterial and venous endothelial cells by immunohistochemistry in sections of umbilical cords from full-term healthy pregnant women; so our results are consistent with theirs. However, we could semi-quantify mRNA of the alpha chain of the receptor and we found expression heterogeneity among individuals. Also, we located the molecule both superficially and intracellularly.
Regarding HMEC-1, Ober et al. (2004a; 2004b) used FcRn-Green Fluorescent Protein (GFP)-transfected HMEC-1 cells to analyze the trafficking of the receptor and its IgG ligand. They demonstrated the capacity of these cells to express both B2M and FcRn alpha chain genes if transfected, but they did not show expression of the endogenous gene. In this study we confirmed that HMEC-1 cells are expressing this molecule on the surface, where it co-localized with CD105, but also within vesicle-like structures in the cytoplasm.

It was interesting to find that HMEC-1 cells homogeneously express higher mRNA levels than HUVECs and villi. In the later two, mRNA expression differed among individuals. This could be due to gender, gestational age or the part of the cord taken to isolate the cells. This was reinforced by the fact that different levels were found with the samples of the same individual (not shown). Another explanation is differential gene regulation. In this regard, Liu et al. (2007) found that stimulation of intestinal epithelial cell lines, macrophage-like THP-1 and freshly isolated human monocytes with TNF- $\alpha$ up-regulated FcRn gene expression. In addition, the TLR ligands LPS and CpG oligodeoxynucleotide enhanced FcRn expression, specifically in THP-1 and monocytes. Addition of NF$\kappa \mathrm{B}$ in TNF-stimulated THP-1 resulted in down-regulation of the FcRn gene. Likewise, the same group showed that IFN- $\gamma$ down-regulated FcRn expression at both mRNA and protein level, which was STAT-1 signaling pathwaydependent in the same cells but detected a relative inability of IFN- $\gamma$ to down-regulate FcRn production in Caco- 2 cells (Liu et al., 2008). These findings indicate that control mechanisms of FcRn transcription regulation differ among cell types (Liu et al, 2008).

In our study, the protein amount seemed not to vary as assessed by confocal microscopy, but we found differences between HMEC-1 and HUVECs by flow cytometry, in this case being HMEC-1 cells less positive. Nevertheless, this could be due to the fact that they were detached with higher concentrations of trypsin; the receptor may be sensitive to the action of the protease, which is reinforced by a similarly lower label of the endothelial marker CD105 (Fig. 2).

In permeabilized cells of both types, some vesiclelike structures filled with FcRn, but not CD105 were seen, which supports that the location of the receptor is superficial and intracellular (probably in endosomes).

The results suggest that the HMEC-1 line could serve as a good model to study FCGRT related processes. However, it is important to consider that it is a transformed line and some of the regulatory mechanisms could be altered. In fact, mRNA levels of FCGRT are much higher in these cells than in HUVECs or villi, although for B2M they were similar (Fig. 1). 
One question that remains unclear is the biological function of the FCGRT in HUVECs in vivo, for these cells are not likely to be involved in transcytosis. Since they belong to macro-vasculature endothelium, it is also unlikely that they have an important role in $\operatorname{IgG}$ level regulation, like microvasculature cells do, but this cannot be ruled out. Of interest is that the absolute and relative mRNA expression of both FCGRT and B2M genes were similar between HUVECs and chorionic villi, but important differences among individuals were found.

\section{Conclusion}

HMEC-1 and HUVEC endothelial cells express the neonatal Fc gamma receptor on the surface as well as intracellularly, enabling them as models for FcRn expression. This grants the possibility of understanding and manipulating the mechanisms in which the receptor is involved. Of importance is that expression of the alpha chain varies of among HUVECs from different individuals.

\section{Acknowledgement}

This article is part of the $\mathrm{PhD}$ Thesis of OALB within the "Programa de Doctorado en Ciencias Biomédicas, Universidad Nacional Autónoma de México (UNAM)". She also was granted with scholarship 174371 from Consejo Nacional de Ciencia y Tecnología (CONACyT).

We are indebted to Dr. Araceli-Paez Arenas and Dr. Felipe Alonso Masso-Rojas, from the National Institute of Cardiology, for their training in HUVECs and HMEC-1 isolation and culture and to Dr. Anaclara Castro-Santana for critical conceptual and language review.

\section{Funding Information}

This work had partial support from the National Council of Science and Technology of Mexico (CONACyT, grant No. 139721) and Federal Funds from INP (No. 060/2011).

\section{Author's Contributions}

All authors read and approved the final manuscript.

Luz Belinda Ortiz-Alegría: Design and conduction of work; data analysis and manuscript writing.

Irma Cañedo-Solares: Experiments design and conduction; review and correction of the manuscript.

Felipe Vadillo-Ortega: Intellectual expertise, review and correction of design and manuscript.

Marisol Castillo-Castrejón: Collection of samples; review and correction of the manuscript.

Dolores Correa: Research line leader, who conceived and designed the study. Data analysis and interpretation and manuscript writing.

\section{Conflict of Interest}

The authors declare no conflicting interest in this work.

\section{References}

Ades, E.W., F.J. Candal, R.A. Swerlick, V.G. George and S. Summers et al., 1992. HMEC-1: Establishment of an immortalized human microvascular endothelial cell line. J. Invest. Dermatol., 99: 683-690. PMID: 1361507

Antohe, F., L. Radulescu, A. Gafencu, V. Ghetie and M. Simionescu, 2001. Expression of functionally active FcRn and the differentiated bidirectional transport of $\mathrm{IgG}$ in human placental endothelial cells. Hum. Immunol., 62: 93-105.

DOI: $10.1016 / \mathrm{S} 0198-8859(00) 00244-5$

Baker, K., T. Rath, W.I. Lencer, E. Fiebiger and R.S. Blumberg, 2012. Cross-presentation of IgGcontaining immune complexes. Cell. Mol. Life Sci., 70: 1319-1334. DOI: 10.1007/s00018-012-1100-8

Baker, K., T. Rath, M. Pyzik and R.S. Blumberg, 2014. The role of $\mathrm{FcRn}$ in antigen presentation. Front. Immunol., 5: 408-408.

DOI: $10.3389 /$ fimmu.2014.00408

Borvak, J., J. Richardson, C. Medesan, F. Antohe and C. Radu et al., 1998. Functional expression of the MHC class I-related receptor, FcRn, in endothelial cells of mice. Int. Immunol., 10: 1289-1298.

DOI: $10.1093 /$ intimm/10.9.1289

Brambell, F.W., W.A. Hemmings and I.G. Morris, 1964. A theoretical model of $\gamma$-globulin catabolism. Nature, 203: 1352-1354. DOI: 10.1038/2031352a0

Cianga, C., P. Cianga, P. Plamadeala and C. Amalinei, 2011. Nonclassical major histocompatibility complex I-like Fc neonatal Receptor (FcRn) expression in neonatal human tissues. Hum. Immunol., 72: 1176-1187. DOI: $10.1016 /$ j.humimm.2011.08.020

Ellinger, I. and R. Fuchs, 2012. HFcRn-mediated transplacental immunoglobulin $G$ transport: Protection of and threat to the human fetus and newborn. Wien. Med. Wochenschr., 162: 207-213. DOI: $10.1007 / \mathrm{s} 10354-012-0085-0$

Ghetie, V., J.G. Hubbard, J.K. Kim, M.F. Tsen and Y. Lee et al., 1996. Abnormally short serum halflives of $\mathrm{IgG}$ in $\beta 2$-microglobulin-deficient mice. Eur. J. Immunol., 26: 690-696. DOI: $10.1002 /$ eji.1830260327

Gupta, S., J.S. Gach, J.C. Becerra, T.B. Phan and J. Pudney et al., 2013. The Neonatal Fc Receptor (FcRn) enhances Human Immunodeficiency Virus type 1 (HIV-1) transcytosis across epithelial cells. PLoS Pathog., 9: e1003776-e1003776.

DOI: $10.1371 /$ journal.ppat.1003776 
Jaffe, E.A., R.L. Nachman, C.G. Becker and C.R. Miinick, 1973. Culture of human endothelial cells derived from umbilical veins. Identification by morphologic and immunologic criteria. J. Clin. Invest., 52: 2745-2756. DOI: 10.1172/JCI107470

Johnson, P.M., P. Trenchev and W.P. Faulk, 1975. Immunological studies of human placentae. Binding of complexed immunoglobulin by stromal endothelial cells. Clin. Exp. Immunol., 22: 133-138. PMID: 765018

Lang, I., M.A. Pabst, U. Hiden, A. Blaschitz and G. Dohr et al., 2003. Heterogeneity of microvascular endothelial cells isolated from human term placenta and macrovascular umbilical vein endothelial cells. Eur. J. Cell. Biol., 82: 163-173. DOI: 10.1078/0171-9335-00306

Liu, X., L. Ye, Y. Bai, H. Mojidi and N.E. Simister et al., 2008. Activation of the JAK/STAT-1 signaling pathway by IFN- $\gamma$ can down-regulate functional expression of the MHC class i-related neonatal Fc receptor for IgG. J. Immunol., 181: 449-463. DOI: 10.4049/jimmunol.181.1.449

Liu, X., L. Ye, G.J. Christianson, J.Q. Yang and D.C. Roopenian et al., 2007. NF-кB Signaling regulates functional expression of the MHC class irelated neonatal Fc receptor for $\mathrm{IgG}$ via intronic binding sequences. J. Immunol., 179: 2999-3011. DOI: 10.4049/jimmunol.179.5.2999

Maidji, E., S. McDonagh, O. Genbacev, T. Tabata and L. Pereira, 2006. Maternal antibodies enhance or prevent Cytomegalovirus infection in the placenta by Neonatal Fc Receptor-mediated transcytosis. Am. J. Pathol., 168: 1210-1226. DOI: 10.2353/ajpath.2006.050482

Marin, V., G. Kaplanski, S. Gres, C. Farnarier and P. Bongrand, 2001. Endothelial cell culture: Protocol to obtain and cultivate human umbilical endothelial cells. J. Immunol. Meth., 254: 183-190. DOI: $10.1016 / \mathrm{S} 0022-1759(01) 00408-2$

Mathur, A., T. Arora, L. Liu, J. Crouse-Zeineddini and V. Mukku, 2013. Qualification of a homogeneous cell-based neonatal Fc Receptor (FcRn) binding assay and its application to studies on Fc functionality of $\mathrm{IgG}$-based therapeutics. J. Immunol. Meth., 390: 81-91.

DOI: $10.1016 /$ j.jim.2013.01.011

Ober, R.J., C. Martinez, X. Lai, J. Zhou and E.S. Ward, 2004a. Exocytosis of IgG as mediated by the receptor, FcRn: An analysis at the single-molecule level. Proc. Natl. Acad. Sci. USA, 101: 11076-11081. DOI: $10.1073 /$ pnas.0402970101

Ober, R.J., C. Martinez, C. Vaccaro, J. Zhou and E.S. Ward, 2004b. Visualizing the site and dynamics of IgG salvage by the MHC class I-related receptor, FcRn. J. Immunol., 172: 2021-2029. DOI: $10.4049 /$ jimmunol.172.4.2021
Paez, A., A.R. Méndez-Cruz, E. Varela, E. Rodriguez and J. Guevara et al., 2005. HUVECs from newborns with a strong family history of myocardial infarction over express adhesion molecules and react abnormally to stimulating agents. Clin. Exp. Immunol., 141: 449-458. DOI: 10.1111/j.1365-2249.2005.02858.x

Perez-Montoyo, H., C. Vaccaro, M. Hafner, R.J. Ober and W. Mueller et al., 2009. Conditional deletion of the MHC class I-related receptor FcRn reveals the sites of IgG homeostasis in mice. Proc. Natl. Acad. Sci. USA, 106: 2788-2793. DOI: $10.1073 /$ pnas.0810796106

Powner, M.B., J.A. McKenzie, G.J. Christianson, D.C. Roopenian and M. Fruttiger, 2014. Expression of neonatal Fc receptor in the eye. Invest. Ophthalmol. Vis. Sci., 55: 1607-1615. DOI: 10.1167/iovs.13-12574

Qiao, S.W., K. Kobayashi, F.E. Johansen, L.M. Sollid and J.T. Andersen et al., 2008. Dependence of antibodymediated presentation of antigen on FcRn. PNAS, 105: 9337-9342. DOI: 10.1073/pnas.0801717105

Radulescu, L., F. Antohe, V. Jinga, V. Ghetie and M. Simionescu, 2004. Neonatal Fc receptors discriminates and monitors the pathway of native and modified Immunoglobulin $G$ in placental endothelial cells. Hum. Immunol., 65: 578-585. DOI: 10.1016/j.humimm.2004.02.029

Rath, T., T.T. Kuo, K. Baker, S.W. Qiao and K. Kobayashi et al., 2013. The immunologic functions of the neonatal Fc receptor for IgG. J. Clin. Immunol. Suppl., 1: S9-17.

DOI: $10.1007 / \mathrm{s} 10875-012-9768-y$

Rodewald, R., 1980. Distribution of immunoglobulin G receptors in the small intestine of the young rat. $\mathrm{J}$. Cell. Biol., 85: 18-32. DOI: 10.1083/jcb.85.1.18

Simister, N.E., C.M. Story, H.L. Chen and J.S. Hunt, 1996. An IgG-transporting Fc receptor expressed in the syncytiotrophoblast of human placenta. Eur. J. Immunol., 26: 1527-1531. DOI: $10.1002 /$ eji. 1830260718

Unger, R.E., V. Krump-Konvalinkova, K. Peters and C.J. Kirkpatrick, 2002. In vitro expression of the endothelial phenotype: Comparative study of primary isolated cells and cell lines, including the novel cell line HPMEC-ST1.6R. Microvasc. Res., 64: 384-397. DOI: 10.1006/mvre.2002.2434

Ward, E.S., S.C. Devanaboyina and R.J. Ober, 2015. Targeting FcRn for the modulation of antibody dynamics. Mol. Immunol., 67: 131-41. DOI: 10.1016/j.molimm.2015.02.007

Ward, E.S. and R.J. Ober, 2009. Chapter 4: Multitasking by exploitation of intracellular transport functions the many faces of FcRn. Adv. Immunol., 103: 77-115. DOI: 10.1016/S0065-2776(09)03004-1

Ward, E.S., J. Zhou, V. Ghetie and R.J. Ober, 2003. Evidence to support the cellular mechanism involved in serum $\mathrm{IgG}$ homeostasis in humans. Int. Immunol., 15: 187-195. DOI: 10.1093/intimm/dxg018 
Xu, Y., R.A. Swerlick, N. Sepp, D. Bosse and E.W. Ades et al., 1994. Characterization of expression and modulation of cell adhesion molecules on an immortalized Human Dermal Microvascular Endothelial Cell line (HMEC-1). J. Invest. Dermatol., 102: 833-837. PMID: 7516395
Zhao, Y., Y. Liu, Z. Chen, C. Korteweg and J. Gu, 2011. Immunoglobulin $\mathrm{G}(\mathrm{IgG})$ expression in human umbilical cord endothelial cells. J. Histochem. Cytochem., 59: 474-488.

DOI: $10.1369 / 0022155411400871$ 